Iustitia Socialis. Revista Arbitrada de Ciencias Jurídicas.

Año V. Vol. V. ํ⒊ Edición Especial. 2020-III:

Universidad Regional Autónoma de los Andes

Hecho el depósito de Ley: FA2016000064 ISSN: 2542-3371

FUNDACIÓN KOINONIA (F.K). Santa Ana de Coro, Venezuela

Carlos Gilberto Rosero-Martínez; Samyr Alexander Pozo-Burbano

http://dx.doi.org/10.35381/racji.v5i3.1145

Derechos humanos y sobrepoblación penal en el Ecuador

Human rights and criminal overpopulation in Ecuador

\author{
Carlos Gilberto Rosero-Martínez \\ ut.carlosrosero@uniandes.edu.ec \\ Universidad Regional Autónoma de los Andes, Tulcán \\ Ecuador \\ https://orcid.org/0000-0001-5064-8516 \\ Samyr Alexander Pozo-Burbano \\ samyrpb10@hotmail.com \\ Universidad Regional Autónoma de los Andes, Tulcán \\ Ecuador
}

Recibido: 31 de octubre de 2020

Revisado: 10 de octubre de 2020

Aprobado: 05 de diciembre de 2020

Publicado: 10 de diciembre de 2020 
Iustitia Socialis. Revista Arbitrada de Ciencias Jurídicas.

Año V. Vol. V. №3. Edición Especial. 2020-III:

Universidad Regional Autónoma de los Andes

Hecho el depósito de Ley: FA2016000064 ISSN: 2542-3371

FUNDACIÓN KOINONIA (F.K). Santa Ana de Coro, Venezuela

Carlos Gilberto Rosero-Martínez; Samyr Alexander Pozo-Burbano

\section{Estimado Editor(a):}

La sobrepoblación en prisiones latinoamericanas es un tema controversial en relación al tema de los derechos humanos, por cuanto existe una cosmovisión social punitiva en contra de los prisioneros, fomentándose una perspectiva de ciudadanos de quinta categoría, lo cual redunda en políticas públicas no efectivas en emplear un verdadero y efectivo proceso de reinserción positiva a la sociedad de los reos, lo cual involucra la necesaria reforma del sistema penitenciario de forma integral, es decir, desde un enfoque preventivo - correctivo, proyectándose la posibilidad de promover los derechos humanos en relación al crecimiento de la persona (Matthews, 2011).

En el Ecuador, el tema del hacinamiento no es novedoso (Pontón \& Torres, 2007), en este sentido, reseñaban en sus conclusiones, la existencia no solo de hacinamiento en las cárceles, sino, de discriminación social, genero, económica, causando serias divisiones no solo en el recinto carcelario, sino, en la sociedad ecuatoriana, lo cual amerita una profunda y seria revisión sociológica del comportamiento humano frente ante la adversidad social que representa la criminalidad y los factores empleados para minimizarla o erradicarla.

Uno de estos factores ha sido incluir la educación en los recintos carcelarios ecuatorianos, sin embargo, (Sumba, et al., 2019), advierte que esta experiencia ha sido desfavorable para los docentes, por cuanto, han narrado no contar con los recursos suficientes, así como percepción de inseguridad en su estadía en el recinto, lo cual, evidencia la falta de profundidad en la aplicación de políticas favorables para el cumplimiento de los derechos humanos en razón de minimizar el hacinamiento desde un enfoque restaurador - preventivo de la dignidad humana para no delinquir (Aldana-Zavala \& Isea, 2018).

En la actualidad reciente, el hacinamiento en las cárceles del Ecuador, se relacionan con el tema salud (Pontón, 2020), la pandemia por COVID-19, deja en evidencia la acelerada vulnerabilidad a los derechos humanos ante la posibilidad de contagios masivos, producto del hacinamiento carcelario, siendo una posibilidad que podría estallar si no se 
maneja con precaución el tema, sobre todo cuando se han confirmado 502 casos de contagio (El Universo 2020).

Lo planteado acelera la vulneración de los derechos humanos, produciendo indisciplina, problemas de salud, carencia de servicios básicos (De-Jesús-Arrias-Añez, et al., 2020), derivándose en una conducta social adversa, siendo necesario aplicar planes o programas integrales en razón de constituir una sociedad equitativa desde los principios de justicia, proyectándose una necesaria y profunda reforma del sistema carcelario ecuatoriano.

Siendo necesario involucrar a las universidades ecuatorianas en un estudio complejo y multidisciplinar con la finalidad de encontrar evidencia científica que permita diseñar planes integrales en procura del crecimiento integral de la persona, esto como un enfoque preventivo - formativo con el objetivo no solo de abordar a los detenidos, sino, de propiciar una formación comunitaria a través de la vinculación social en razón de estrechar un lazo productivo entre universidad - sociedad desde un paradigma social de abordaje de los factores criminógenos como acción social coherente a la conformación de una sociedad bioética en preservación de los derechos humanos fundamentales de todos sus ciudadanos.

\section{AGRADECIMIENTO}

A la Universidad Regional Autónoma de Los Andes; por motivar el desarrollo de la Investigación.

\section{REFERENCIAS CONSULTADAS}

Aldana-Zavala, J., \& Isea, J. (2018). Derechos Humanos y Dignidad Humana [Human Rights and Human Dignity]. IUSTITIA SOCIALIS, 3(4), 8-23.

De-Jesús-Arrias-Añez, J, Plaza-Benavides, B, \& Herráez-Quezada, R. (2020). Interpretación del sistema carcelario ecuatoriano [Interpretation of the Ecuadorian prison system]. Revista Universidad y Sociedad, 12(4), 16-20. 
Iustitia Socialis. Revista Arbitrada de Ciencias Jurídicas.

Año V. Vol. V. №3. Edición Especial. 2020-III:

Universidad Regional Autónoma de los Andes

Hecho el depósito de Ley: FA2016000064 ISSN: 2542-3371

FUNDACIÓN KOINONIA (F.K). Santa Ana de Coro, Venezuela

Carlos Gilberto Rosero-Martínez; Samyr Alexander Pozo-Burbano

El Universo. (2020). La presencia del COVID-19 en cárceles de Ecuador causa alarma; hay 502 casos confirmados [The presence of COVID-19 in prisons in Ecuador causes alarm; there are 502 confirmed cases (2020)]. Recuperado de: https://n9.cl/arip

Matthews, R. (2011). Una propuesta realista de reforma para las prisiones en Latinoamérica [A realistic reform proposal for prisons in Latin America]. Política criminal, 6(12), 296-338. https://dx.doi.org/10.4067/S0718-33992011000200003

Pontón, D. (2020). Las cárceles y el coronavirus en Ecuador: ¿un coctel explosivo? [ Prisons and coronavirus in Ecuador: an explosive cocktail? Recuperado de https://n9.cl/5bft

Pontón, J, \& Torres, A. (2007). Cárceles del Ecuador: los efectos de la criminalización por drogas [Prisons in Ecuador: the effects of drug criminalization]. URVIO, Revista Latinoamericana de Estudios de Seguridad, (1),55-73.

Sumba, N., Cueva, J., \& López, R. (2019). Experiencias en el ejercicio de la educación superior en la prisión, desde la perspectiva del docente. Estudio de caso: Guayaquil, Ecuador [Experiences in the Exercise of Higher Education in Prison from the Teacher's Perspective. Case Study: Guayaquil, Ecuador]. Páginas De Educación, 12(2), 72-88. https://doi.org/10.22235/pe.v12i2.1838

(C2020 por los autores. Este artículo es de acceso abierto y distribuido según los términos y condiciones de la licencia Creative Commons Atribución-NoComercial-Compartirlgual 4.0 Internacional (CC BY-NC-SA 4.0)

(https://creativecommons.org/licenses/by-nc-sa/4.0/). 